\title{
Gheorghe Popa et al., Dicționarul asociativ al limbii române, I, Editura Junimea, Iași, 2016, 365 p.
}

\author{
Dinu Moscal* \\ Institutul de Filologie Română „A. Philippide”, Str. Th. Codrescu 2, 700481 Iași, România
}

Trăsătura definitorie a dicționarelor asociative constă în abordarea netradiţională a lexicului. Un dicționar clasic se caracterizează prin ordonarea alfabetică a cuvintelor și explicarea acestora printr-o definiție. În istoricul lexicografiei au mai existat încercări de tratare netradițională/ neconvențională a lexicului. Obiectivul acestora a fost ameliorarea organizării tradiţionale, care urmează ordinea alfabetică (strict formală), prin introducerea indicației raporturilor bazate pe semnificație sau chiar a raporturilor $\mathrm{cu}$ contextul imediat în care se află realitatea desemnată. În acest fel, gradul de utilitate este superior, deoarece astfel de asocieri îl conduc pe utilizator și la denumirea ideilor și sau a realităților asociate, chiar și atunci cînd acestea nu îi sînt cunoscute. Dicţionarele asociative prezintă, parțial, și trăsături ale acestor dicționare neconvenționale anterioare, de aceea pot fi încadrate în această direcție, însă se și deosebesc printr-o abordare care depășește perspectiva acestora. Concret, asocierile nu sînt supuse atenției lexicografului; acesta doar consemnează asocierile (libere) ale vorbitorului. Această trăsătură arată că nu există o abordare metalingvistică, pentru că lexicograful nu intervine în asocierile făcute de subiecții aleși să constituie un grup reprezentativ pentru vorbitorii unei limbi. În plus, dicționarele asociative au în vedere doar o parte din lexicul fundamental al unei limbi, cel prin care se poate ajunge la o anumită percepție afectivă a lumii. $\mathrm{O}$ scurtă trecere în revistă a altor tipuri de dicționare în care asocierea a avut un rol de structurare, precum și comparația cu acestea pot să aibă un aport important în distingerea specificului dicționarelor asociative, deoarece unele aspecte sînt comune.

Mai întîi trebuie evidenţiată diferența dintre asocierile lingvistice şi cele extralingvistice. Asocierile lingvistice au la bază fie semnificația, fie forma unui cuvînt, în timp ce asocierile extralingvistice au la bază desemnatul (obiectul) la care trimite cuvîntul. Pe baza asocierilor lingvistice sînt realizate dicționarele de sinonime sau de antonime (asocieri bazate pe semnificația cuvîntului), dicționarele de omonime, de paronime sau de rime (asocieri bazate pe forma cuvîntului). Asocierile bazate pe semnificație apar şi în dicționarele tradiționale, dar nu au un rol în organizarea lor; ele apar doar în cadrul articolelor lexicografice (sensul în anumite expresii; trimiterile la sinonime, dar și la hiperonime, hiponime sau antonime în cadrul definiției). Asocierile extralingvistice, adică cele bazate pe desemnat (realitatea desemnată), apar în dicționarele ce fructifică teoria cîmpurilor semantice orientată/ deviată către ordinea naturală a realităţii desemnate.

Un prim dicționar neconvențional este Thesaurus of English Words and Phrases (Roget, 1946 [1852]), care îl definește prin obiectivul său diferit:

"The purpose of an ordinary dictionary is simply to explain the meaning of words; and the problem of which it professes to furnish the solution may by stated thus - The word being given, to find its signification, or the idea it is intended to convey. The object aimed at in the present undertaking is exactly the converse of this: namely, - The idea being given, to find the word, or words, by which that idea may be most fitly and aptly expressed. For this purpose, the words and phrases of the language are here classed, not according to their sound or their orthography, but strictly according to their signification".

[Scopul unui dicționar obișnuit este pur și simplu să explice sensul cuvintelor; iar problema pentru care îşi propune să ofere o soluție poate fi prezentată astfel: fiind dat un cuvînt, să se găsească semnificația sau ideea pe care acesta trebuie să o transmită. Obiectivul urmărit în

\footnotetext{
*Adresă de corespondență: dinu.moscal@gmail.com.
} 
cadrul prezentului demers este tocmai contrariul acestui lucru, și anume: dată fiind o idee, să se găsească cuvântul sau cuvintele prin care ideea poate fi exprimată cît mai exact și cît mai adecvat. Avînd acest scop, cuvintele și expresiile limbii sînt ordonate aici nu în funcție de sunetul lor sau de ortografia lor, ci strict în funcție de semnificația lor.]

(Roget, 1946 [1852], p. xiii).

Dicționarul lui Sanders (1873-1877) este o realizare de același tip pentru limba germană, iar titlul oferă prin el însuşi o informație despre modul în care este tratat lexicul: Deutscher Sprachschatz, geordnet nach Begriffen zur leichten Auffindung und Auswabl des passenden Ausdrucks. Aceeași direcție, combinată însă cu cea convențională, se regăsește și în Dictionnaire analogique de la langue française. Répertoire complet des mots par les idées et des idées par les mots, elaborat de P. Boissière, pentru care „un dictionnaire, pour être complet, devrait se diviser en deux parties distinctes dont l'une peut servir à trouver la signification, et l'autre à trouver la forme [un dicționar, pentru a fi complet, ar trebui împărțit în două părți distincte, dintre care una să se poată folosi pentru a găsi semnificația, iar cealaltă pentru a găsi forma]" (Boissière, 1862, Préface, p. II).

Argumentul unor astfel de dicționare este gradul superior de utilitate. Acestea servesc nu doar la definirea mai clară a unui cuvînt, ci și la găsirea unui cuvînt necunoscut, despre care utilizatorul are doar idee mai mult sau mai puţin clară. Una dintre exemplificările lui Boissière (1862, Explications indispensables, p. I) în acest sens este găsirea cuvîntului pentru ansamblul de petale viu colorate din interiorul unei flori: un dicționar tradițional nu este util într-o astfel de situație, însă dicţionarul său face această asociere în cadrul articolului floare, unde utilizatorul va găsi cuvîntul corolă, precum şi definiția aferentă.

O altă direcție neconvențională este reprezentată de dicționarele care au încercat să fructifice teoria cîmpurilor semantice (Casares, 1942; Niobey, 1979), la care se poate adăuga și Dornseiff (1934), direcție în care se trece de la o ordine a semnificației înspre o ordine a desemnatului, așa cum se observă și din titlul dicţionarului: Der deutsche Wortschatz nach Sachgruppen.

Dicționarele menționate sînt și ele bazate pe asocieri, ceea ce implică o depășire a modului de redactare a unei lucrări lexicografice obişnuite, caracterizată prin ordonare alfabetică și definire a cuvîntului. Asocierile semantice sînt însă rezultatul analizei lexicografului. Inclusiv dicționarul lui Dornseiff (1934) reflectă o organizare ce urmează o metodologie bine determinată. Obiectivul lor este creșterea utilității în scopul unei cît mai bune cunoașteri a lexicului respectivei limbi.

Spre deosebire de cele de mai sus, un dicționar asociativ oferă o ordine a asocierilor nesupusă analizei metalingvistice. Asocierile semantice pe care se bazează dicționarele menționate anterior corespund în mare măsură observațiilor făcute de Saussure în privința cimpurilor asociative sau paradigmatice (menționate în introducerea lucrării recenzate aici, p. 5). Un dicționar asociativ redă asocierile de orice tip făcute de vorbitor, asocieri bazate pe semnificație (nespecifice, prezente și în dicționarele netradiționale anterioare, de exemplu, în cazul cuvîntului codru, din cele 812 răspunsuri, 230 sînt asocieri cu pădure), pe (obiectul) desemnat (calcăruță, 796/49), pe o percepție individuală a realității desemnate (părinte-totul, înger, 825/3, 2) sau pe experiența generală legată de realitatea desemnată prin cuvînt (foame-mîncare, sete, 799/263, 31; ougăină, pui, mîncare, 860/296, 67, 45). Această ultimă componentă reprezintă trăsătura de bază a dicționarelor asociative în ceea ce privește conținutul lor. Asocierile bazate pe experiența generală conturează modul în care o comunitate lingvistică își reprezintă lumea (pornind de la cuvinte). Spre deosebire de toate celelalte tipuri de dicționare, al căror obiectiv este cunoașterea cuvintelor, obiectivul unui dicționar asociativ este cunoașterea modului în care o comunitate lingvistică îşi reprezentă lumea pornind de la cuvinte. În mod evident, perspectiva este complet diferită față de lucrările lexicografice obişnuite, iar acest lucru se explică prin originea dicţionarelor asociative.

Conceptul de dicționar asociativ se datorează în mare măsură școlii psiholingvistice ruse și în special, în ultimele trei decenii, școlii de psiholingvistică de la Moscova. Lucrările de bază din care descinde această direcție de cercetare sînt Kent \& Rosanoff (1910) și Vîgotski (1972 [1934]). Primul este un studiu de psihiatrie, iar cel de-al doilea unul de psihologie și psiholingvistică. 
În Kent \& Rosanoff $(1910)^{1}$ se stabileşte, pe baza frecvenței, o listă de 100 de cuvinte-stimul și se face o statistică a asocierilor normale pe baza răspunsurilor a 1000 de subiecți, urmată de o statistică a asocierilor pentru aceeaşi listă de cuvinte pentru grupuri cu anumite afecțiuni mintale, cu scopul de a avea un rezultat palpabil în privința gradului de deviere de la normalitate. Ca rezultat general, tendințele de asociere normală redate procentual sînt $6,8 \%$ - reacții individuale, $1,5 \%$ - reacții îndoielnice și 91,7\% reacții comune, spre deosebire de pacienții afectați de diverse boli mintale, în cazul cărora procentele au fost diferite: $26,8 \%$ - reacții individuale, $2,5 \%$ reacții îndoielnice şi 70,7\% - reacții comune (Kent \& Rosanoff, 1910, p. 40, 317). Finalitatea studiului psihiatrilor de la Kings Park State Hospital constă în sesizarea diferențelor de reprezentare a lumii la pacienții cu afecțiuni mintale.

Lev S. Vîgotski, psiholog rus care se remarcă prin poziția sa sceptică privind teoria behavioristă, consideră că psihicul uman se dezvoltă în urma percepției mediului prin intermediul limbajului. Conform perspectivei acestuia, „semnificațiile cuvintelor se dezvoltă”, iar „asociația care leagă cuvîntul și semnificația sa se poate fixa sau poate slăbi, se poate îmbogăți printr-o serie de legături cu alte obiecte de același gen, se poate extinde asupra unui cerc mai larg de obiecte sau, dimpotrivă, poate avea loc o îngustare sau o limitare a acestui cerc" (Vîgotski, 1972 [1934], p. 252-253). O primă concluzie a acestui fapt privește nivelul lingvistic, și anume că, „dacă semnificația cuvîntului se poate schimba în natura sa internă, înseamnă că se schimbă și relația dintre gîndire și cuvint”" (ibidem, p. 258), iar o a doua privește reprezentarea lumii în conștiința umană prin limbă: „Dacă conștiința, care sesizează și gîndește, dispune de diferite mijloace de reflectare a realității, atunci acestea reprezintă și diferite tipuri de conștiință. De aceea, gîndirea și limbajul reprezintă cheia pentru înțelegerea naturii conștiinței umane" (ibidem, p. 307).

Combinarea acestor două direcții de studiu a condus la stabilirea unor norme necesare elaborării unui dicționar asociativ, care să reprezinte amprenta percepției lumii pentru o anumită comunitate lingvistică. Lucrările care stabilesc liniile directoare ale cercetării structurii asociative a limbajului apar în deceniile al șaptelea și al optulea ale secolului trecut și îi aparţin lui A.A. Leontiev² ${ }^{2}$ lingvist de orientare psihologistă $\breve{a}^{3}$ cu o poziție importantă în spațiul rus. Acest tip de cercetare se identifică propriu-zis prin rezultatele psiholingvisticii ruse ${ }^{4}$, în special prin direcția asumată de școala de psiholingvistică de la Moscova:

„Depuis les années 90 l'école de psycholinguistique de Moscou a commencé à élaborer une nouvelle base théorique pour les études d'ethnopsycholinguistique, centrées sur l'analyse de la particularité de la conscience linguistique spécifique d'une culture nationale donnée et sur l'idée que l'incompréhension dans la communication interculturelle est due à la différence des consciences nationales des acteurs de la communication. La recherche de nouvelles voies de travail a amené les spécialistes à la conception de l'ontologie interculturelle de l'analyse des consciences nationales (ethniques), quand les images de la conscience d'une culture nationale sont analysées en contraste avec celles d'une autre culture".

[Începînd cu anii 90, școala de psiholingvistică de la Moscova a început să elaboreze o nouă bază teoretică pentru studiile de etnopsiholingvistică, axate pe analiza particularității conștiinței lingvistice specifice a unei anumite culturi naționale şi pe ideea că intercomprehensiunea în cadrul comunicării interculturale se datorează diferenței de conștiință națională a actorilor din actul comunicării. Analiza unor noi căi de cercetare i-a condus pe specialiști la concepția unei ontologii interculturale a analizei conștiinţelor naţionale (etnice), atunci cînd imaginile conștiinței unei culturi naționale sînt analizate în contrast cu cele

\footnotetext{
${ }^{1}$ Studiul lor are la bază metoda de cercetare a psihologului J.M. Cattell (1886a, 1886b, 1887), folosită pentru a observa diferența dintre percepție și gîndire, pornind de la măsurarea timpului necesar pentru senzația provocată de stimul (recunoașterea acestuia) și a timpului necesar pentru procesul mintal provocat de stimul (cuvîntul ce desemnează respectivul stimul).

${ }^{2}$ Fiul psihologului A.N. Leontiev, coleg și continuator al lui Lev S. Vîgotski. De altfel, A.A. Leontiev este autorul unor monografii dedicare fiecăruia dintre ei.

${ }^{3}$ Prima teză de doctorat este un studiu monografic al perspectivei lingvistice a lui Baudoin de Courtenay, iar următoarele două sînt lucrări de psiholingvistică.

${ }^{4}$ Orientare cu un trecut bine cunoscut, în special prin școala de la Harkov.
} 
ale unei alte culturi.]

(Debrenne et al., 2008, p. 1117-1118)

Cercetările școlii psiholingvistice ruse privind asocierilor lingvistice sînt dedicate în primul rînd limbii ruse, dar sint aplicate și la alte limbi, precum franceza, engleza și spaniola (cf. Debrenne \& Ufimsteva, 2011). Conform autorilor Prefeței lucrării recenzate aici, pînă în prezent „au fost elaborate și editate dicționare asociative pentru cîteva zeci de limbi” (p. 7).

Autorii Dicționarului asociativ al limbii române (Gheorghe Popa, Ala Sainenco, care sînt și autorii Prefeței, Valentina Prițcan, Viorica Popa, Elena Lacusta, Lilia Trinca și Lucia Popa) sînt toți originari din Republica Moldova, ceea ce a facilitat un contact neintermediat cu teoriile și rezultatele școlii psiholingvistice ruse, precum şi colaborarea $\mathrm{cu}$ grupul de cercetători de la Academia de Științe din Rusia (care au elaborat Dicționarul asociativ al limbii ruse), colaborare concretizată printr-un stagiu al tuturor autorilor la Academia din Rusia (p. 8-9).

Dicționarul cuprinde 508 cuvinte-stimul, iar răspunsurile vin din cca 5000 de anchete realizate în întreg arealul românesc (România şi Republica Moldova), bazate pe chestionare de 100 de cuvinte (p. 9-10). Raportul dintre numărul de cuvintestimul din dicționar (508) și numărul de cuvintestimul (100) din chestionare are ca rezultat un număr total de răspunsuri (asocieri) variabil, în general între 750 și 800 (dar 650 la orgolios, 840 la familie). Răspunsurile la cuvintele-stimul nu sînt evaluate de către autorii dicționarului, fapt ce se reflectă în înregistrarea următoarelor asocieri: a) forme morfologice diferite pentru același cuvint, de exemplu, degete (47 din 801$)$ și deget (14 din 801) la cuvîntul-stimul palmă; b) răspunsuri individuale și răspunsuri îndoielnice (aşa cum au fost ele clasificate în Kent \& Rosanoff, 1910, p. 40, 317), de exemplu asocierile individuale cu oiconimele Avram Iancu, Bălți, Brăila etc. pentru cuvîntul-stimul acasă, data în care s-a completat răspunsul în chestionar sau data/anul de naștere pentru cuvîntul-stimul an sau cuvîntul-stimul dată, respectiv asocieri îndoielnice, precum răspunsul verde ( 2 din 755 ) pentru cuvîntulstimul ac. Aceste mărci ale spontaneităţii și ale liberei asocieri ale subiecților anchetați oferă o imagine vie celui ce consultă dicționarul.

Pe lîngă importanța sa în lingvistică, Dicționa- rul asociativ al limbii române poate fi util în mai multe domenii. Antropologii, sociologii, etnologii şi culturologii vor găsi în acest dicționar probe reale ale trăsăturilor arealului comunității lingvistice române. De exemplu, cuvîntul-stimul stînga (cu 807 răspunsuri) are, pe lîngă asocierile comune dreapta (387), mînă (79), direcție (22), parte (15), mîna (13) etc. și asocieri precum: ghinion (6), rău (6), neserios (4), nedrept (2), neîncredere (2) sau chiar Hitler (1) și totalitarism (1). Probabil că asocierile pentru cuvîntul-stimul dulce (cu 781 de răspunsuri) sînt utile și în afara domeniilor umaniste: ciocolată (109), amar (80), miere (67), zahăr (61), prăjitură (53), bun (50), acru (32), bomboană (18), bomboane (18) etc. Asocierile cu ființe umane pentru cuvîntul-stimul asculta (cu 784 de răspunsuri) sînt (cele cu frecvența mai mare de 1): părinții (5), profesor (5), mama (4), copil (3), părinți (3), profesori (3), psibolog (2). Unele asocieri indică nu doar diversitatea subiecților anchetaţi, ci și realități din mediul rural mai puțin cunoscute în general: cuvîntul-stimul miez (cu 768 de răspunsuri) are și răspunsul coasă (2).

O analiză a conceptului de 'frumusețe' la români are în răspunsurile la cîteva cuvinte-stimul din dicționar o imagine cu un grad mai ridicat de obiectivitate. Pentru cuvîntul-stimul frumoasă (cu 776 de răspunsuri) asocierea cu cea mai mare frecvență este fată (85), după care urmează antonimul urîtă (42), sinonimul drăguţă (37), apoi femeie (36), eu (17), minunată (17), plăcută (15), atrăgătoare (13), gingaşă (13) etc. Situația din cazul cuvîntului-stimul frumos (cu 763 de răspunsuri) nu este nici pe departe asemănătoare: urît (76), plăcut (39), drăguț (38), băiat (24), chipeş (21), copil (20), minunat (16), peisaj (15), eu (13), atrăgător (11), bărbat (11), arătos (10), natură (10), suflet (10) etc. Pentru cuvîntulstimul fată (cu 826 de răspunsuri) asocierea cu cea mai mare frecvență este frumoasă (101), după care urmează băiat (88), frumusețe (40), domnişoară (28), femeie (24), frumos (21) etc. Pentru cuvîntul-stimul băiat (cu 797 de răspunsuri) frecvențele cele mai mari le au fată (129), copil (60), frumos (38), bărbat (22), om (22), bun (18) etc. Raportarea la fată reflectă situația lui frumos față de frumoasă. Femeie nu apare în calitate de cuvînt-stimul, deși poate că sar fi cuvenit să apară. Pentru cuvîntul-stimul bărbat (cu 798 de răspunsuri) frecvențele cele mai mari le au femeie (134), om (79), putere (75), puternic (44), soț (30), tata (22), frumos (19), inalt (19), barbă 
(14) etc. Datele despre subiecții respondenți, în special diferențierea după sex, dar și cea după vîrstă (informații prezente cu siguranță în fondul de date al proiectului) ar contribui la o aprofundare a acestei analize.

$\mathrm{O}$ analiză contrastivă a răspunsurilor pentru termeni sinonimi conduce, de asemenea, către o cunoaștere la un alt nivel. Opoziția bilaterală noapteintuneric relevă un contrast poate nebănuit în ceea ce privește sentimentul de teamă, deși prima asociere este reciprocă. Pentru noapte (817 răspunsuri) avem următoarele asocieri: intuneric (204), zi (103), stele (71), somn (58), lună (46), liniște (21), lungă (19), negru (19), albă (14), bună (12), albastră (10), romantic (10), seară (10), frică (9), beznă (8) etc. Pentru intuneric (808 răspunsuri) avem: noapte (173), frică (95), negru (83), lumină (81), beznă (70), teamă (17), liniște (12), lună (10), moarte (9), seară (8), la frecvența 6 apare cuvîntul spaimă, iar la frecvența 2 groază și înfricoşător. Pentru cuvîntulstimul teamă (808 răspunsuri) ordinea primelor asocieri (după frecvență) este: frică (468, așadar 57,9\%), spaimă (25), intuneric (23), mare (9), durere (7), nesiguranță (5), singurătate (5), şarpe (5), după care urmează 9 răspunsuri cu frecvența 4 , dintre care și de intuneric, 10 răspunsuri cu frecvența 3, 24 de răspunsuri cu frecvența 2, printre care și noapte. Frică nu a fost selectat între cuvintele-stimul.
Dicționarul oferă informaţii pentru diverse domenii și tematici. La cuvîntul-stimul codru, Eminescu apare cu frecvența 12 (din 812 ) și ocupă poziția a opta, în timp ce la cuvîntul-stimul pădure, Eminescu apare cu frecvența 1 (din 803). La cuvîntulstimul poveste (cu 821 de răspunsuri), Ion Creangă apare cu frecvența 16, Harap-Alb cu frecvența 8, Petre Ispirescu nu apare deloc, dar apar Decameron, Decameronul, Grimm și frații Grimm cu frecvența 1. La cuvîntul-stimul poet, asocierile cu poeți sînt: Eminescu (116, prima poziție), Bacovia (5), Vieru (3), Creangă (2), Puşkin (2), după care urmează numele cu frecvența 1: Ana Blandiana, Arghezi şi Stănescu. Frecvența cea mai ridicată pentru cuvîntul-stimul politic (789 de răspunsuri) o au cuvintele minciună (69) și minciuni (26) (alături de partid, tot cu 26). Frecvența cea mai ridicată pentru cuvîntul-stimul politică ( 765 de răspunsuri) o au cuvintele minciună (74), minciuni (35) şi corupție (25).

Frecvența asocierilor indică schemele cognitive care reprezintă cel mai adesea stereotipuri sociale. Cercetătorii din diverse domenii trebuie să profite din plin de aceste informații. Autorii nu au anunțat în acest prim volum ce va urma în volumul al doilea. Probabil că este vorba despre un dicționar invers al asocierilor, care ar aduce un aport esențial în utilizarea datelor din primul volum.

\section{Bibliografie}

Boissière, P. (1862). Dictionnaire analogique de la langue française. Répertoire complet des mots par les idées et des idées par les mots, Aug. Boyer et $\mathrm{C}^{\mathrm{ie}}$, Paris.

Casares, J. (1942). Diccionario Ideológico de la Lengua Española, Gustavo Gili, Barcelona.

Cattell, J.M. (1886a). The time it takes to see and name objects, în „Mind”, XI, 1886, p. 63-65.

Cattell, J.M. (1886b). The time taken up by cerebral operations, în „Mind”, XI, p. 220-242, 377-392, 524-538.

Cattell, J.M. (1887). Experiments on the association of ideas, în „Mind”, XII, p. 68-74.

Debrenne, M. \& Ufimsteva, N.V. (2011). L'apport des dictionnaires d'associations lexicales aux études de sémantique, în "Syntaxe et sémantique" (12), p. 121-137.

Debrenne, M. et al. (2008), L'étude des champs associatifs du français: création d'un dictionnaire des normes associatives, în Durand, J. et al. (éds.), Congrès Mondial de Linguistique Française - CMLF'08, Institut de Linguistique Française, Paris, p. 1117-1127, CrossRef.

Dornseiff, F. (1934). Der deutsche Wortschatz nach Sachgruppen, Walter de Gruyter \& Co., Berlin und Leipzig.

Kent, G.H. \& Rosanoff, A.J. (1910). A study of association in insanity, în „American Journal of Insanity”, vol. LXVII, nr. 1, p. 37-96, CrossRef; nr. 2, p. 317-390, CrossRef.

Niobey, G. (1979). Nouveau Dictionnaire Analogique, Larousse, Paris.

Postman, L. (1970). Norms in word association, Academic Press, New York.

Roget, P.-M. (1946 [1852]). Thesaurus of English Words and Phrases, Longmans-Green, London-New York-Toronto.

Sanders, D. (1873-1877). Deutscher Sprachschatz, geordnet nach Begriffen zurleichten Auffindung und Auswabldespassenden Ausdrucks, Hoffmann \& Campe, Hamburg.

Vîgotski, L.S. (1972 [1934]). Opere psihologice alese, volumul II, Gîndire și limbaj, Editura Didactică și Pedagogică, București. 